\title{
Assessment of Inotropic and Vasodilating Effects of Milrinone Lactate in Patients with Dilated Cardiomyopathy and Severe Heart Failure
}

\author{
Edson Antonio Bregagnollo, Adjair Humberto Fortes, Antonio Carlos Cicogna
}

Botucatu, SP - Brazil

Objective - To assess the hemodynamic and vasodilating effects of milrinone lactate (ML) in patients with dilated cardiomyopathy (DCM) and New York Heart Association (NYHA) class III and IV heart failure.

Methods - Twenty patients with DCM and NYHA class III and IV heart failure were studied. The hemodynamic and vasodilating effects of $M L$, administered intravenously, were evaluated. The following variables were compared before and during drug infusion: cardiac output (CO) and cardiac index (CI); pulmonary capillary wedge pressure (PCWP); mean aortic pressure (MAP); mean pulmonary artery pressure (MPAP); mean right atrial pressure (MRAP); left ventricular systolic and end-diastolic pressures (LVSP and $L V E D P$, respectively); peak rate of left ventricular pressure rise (dP/dt); systemic vascular resistance (SVR); pulmonary vascular resistance (PVR); and heart rate (HR).

Results - All patients showed a significant improvement of the analysed parameters of cardiac performance with an increase of $\mathrm{CO}$ and $\mathrm{CI}$; a significant improvement in myocardial contractility $(d P / d t)$ and reduction of the LVEDP; PCWP; PAP; MAP; MRAP; SVR; PVR. Were observed no significant increase in HR occurred.

Conclusion - Milrinone lactate is an inotropic dilating drug that, when administered intravenously, has beneficial effects on cardiac performance and myocardial contractility. It also promotes reduction of SVR and PVR in patients with DCM and NYHA class III and IV of heart failure.

Key-words: heart failure, inotropic agents, milrinone

Faculdade de Medicina de Botucatu - UNESP. Support: FAPESP - Project number 91-3666-9.

Mailing address: Edson Antonio Bregagnollo - Faculdade de Medicina de Botucatu - UNESP. Serviço de Hemodinâmica e Angiografia Digital - 18618-000

- Botucatu, SP - Brazil
Despite classic therapeutics with digitalis, diuretics, vasodilators, and angiotensin converting enzyme (ACE) inhibitors, patients with DCM and NYHA class III and IV congestive heart failure (CHF) often present with episodes of cardiac decompensation. During these episodes, the therapeutics of $\mathrm{CHF}$ requires the intravenous administration of either inotropic or vasodilating agents, or both. Vasodilating therapy with sodium nitroprusside has proven effective in patients with left ventricle failure, but arterial hypotension is its main side effect. The inotropic agents (dopamine and dobutamine) that act through $\alpha$-adrenergic stimulation also have proven efficacy in short-term treatment of $\mathrm{CHF}^{1,2}$. In addition to the intense positive inotropic activity, these agents also have adverse side effects, such as a significant increase in HR, an increase in oxygen consumption by the myocardium, an increase in myocardial irritability, and elevation of systemic and pulmonary vascular resistances ${ }^{3-5}$. It should be emphasized that patients with DCM in an advanced stage often exhibit reduction in the number or sensitivity of $\alpha$-adrenergic receptors, or both, and this can restrict the plain activity of sympathicomimetic agents ${ }^{6,7}$.

From 1978 on, a new category of drugs has appeared, the so-called inodilators, to be used intravenously in the treatment of CHF of different causes ${ }^{8-10}$. They are the bipiridines characterized by the concomitance of positive inotropic properties and peripheric and pulmonary arterial vasodilating properties. The bipiridines act by inhibiting the isoenzyme of type III phosphodiesterase, promoting an increase in intracellular cyclic AMP in the myocardium and in the vascular smooth muscle ${ }^{5,10-13}$. This results in an increase of concomitant inotropism and vasodilatation that are independent from the adrenergic pathways and from the $\mathrm{Na}^{+} \mathrm{K}^{+}$ATPase system, used by sympathicomimetic agents and digitalis, respectively.

Currently, for clinical use there are two inhibiting agents of phosphodiesterase available: amrinone and milrinone. There are reports in the literature ${ }^{14}$ showing that milrinone lactate (ML) has greater inotropic activity and smaller 
incidence of adverse side effects than amrinone. Both drugs are used in the treatment of CHF of different causes.

The objective of this study was to evaluate ML in patients with DCM and NYHA class III or IV CHF. The acute effects of the intravenous administration of ML in patients were analysed with regard to cardiac performance and myocardial contractility, as were the systemic and pulmonary arterial vasodilating effects.

\section{Methods}

We analysed 20 patients, 11 males and 9 females, ranging in age from 35 to 63 years. They had DCM and were in NYHA class III and IV CHF ( 5 patients were in class III and 15 in class IV). Althrough, conventional therapeutics with digitalis, vasodilators, diuretics, and ACE inhibitors were used, patients were still in heart failure. Prior to the study protocol, the patients underwent clinical examination, ECG, chest roentgenogram, and Doppler echocardiogram.

The criteria for inclusion in the study were the following: a) the patient, female or male, should be $>18$ years of age; b) have NYHA class III or IV CHF; c) have DCM; d) have a cardiothoracic index of $>0,60$; e) have diffuse hypokinesia of the left ventricle (LV) on echocardiogram and ventriculography; f) sinus rhythm; g) no coronary artery obstruction and LV end-diastolic pressure $\geq 16 \mathrm{mmHg}$. Patients with cardiac valvular diseases, Chagas' cardiomyopathy, ischemic cardiomyopathy, hypertension, and significant tricuspid insufficiency were excluded from the study.

The oral medication patients were taking was kept at the same dosages throughout the ML study protocol.

To determine the causes of the cardiomyopathy, all patients underwent right and left cardiac catheterization through brachial via and under local anesthesia with $2 \%$ lidocaine. Right catheterization was performed through the median basilic vein, with the introduction of a thermodilution catheter 7F. Its distal extremity was located in the right branch of the pulmonary artery. The catheterization of the left ventricle was retrogradely performed through the right brachial artery, using the catheter Sones 8F. All patients underwent coronary angiography and ventriculography.

For pressure registration, a manometrical system was used. This system consisted of a Statham P23Db transductor connected to a VR 1205 amplifier of a VR 12 recorder (Electronics for Medicine). This manometrical system has already been evaluated in our laboratory and has dynamic characteristics appropriate for the evaluations performed in this study ${ }^{15}$. The mean plane of the thorax was taken as the zero pressure reference level for the pressure values.

The changes in the contractile state of the myocardium were evaluated by the analysis of the behavior of the peak rate of the left ventricular pressure rise $(\mathrm{dP} / \mathrm{dt})$. For this, the left ventricle pressure signal was continually differentiated electronically by unfiltered RC circuit. The value of $\mathrm{dP} / \mathrm{dt}$ was the arithmetic mean value of 10 consecutive cardiac beats.
The cardiac output (CO) was determined by the thermodilution method using the monitor of cardiac output Anamed model 7800 . For each patient studied, the $\mathrm{CO}$ value was obtained using the arithmetic mean value of 5 consecutive determinations, which did not did not show a difference greater than $5 \%$ between the highest and the lowest values obtained.

Study protocol - When the diagnostic evaluations were finished, a period of 30 minutes was observed before starting the evaluation protocol. With the patients at basal condition, the records of the following variables were obtained: HR; PCWP; MAP; MPAP; MRAP; LVSP and LVEDP; $\mathrm{CO}$ and $\mathrm{CI}$; systolic volume and index (SV and SI, respectively); dP/dt; systemic and pulmonary vascular resistances (SVR and PVR, respectively). For the determination of CI, SV, SI, SVR, and PVR, pattern calculations and formulas established in the literature were used.

After the variables at basal condition were recorded, an initial bolus of $50 \mu \mathrm{g} / \mathrm{kg}$ of ML was administered in about 10 minutes, followed by intravenous continuous infusion of increasing doses of $0.50,0.625$, and $0.75 \mu \mathrm{g} / \mathrm{kg} / \mathrm{min}$ of ML up to the obtainment of a maximum increase in the $\mathrm{CO}$ without adverse side effects. The following side effects were established as adverse: a) increase of HR and/or decrease of the MAP > $15 \%$ in relation to basal values, or both; b) ventricular extrasystoles $>10 /$ minute.

Once established, the dose of ML that promoted the highest increase of $\mathrm{CO}$ was maintained by continuous infusion. One hour after the start of this dose, another measurement of all variables evaluated at basal condition was recorded. A 5\% glucose solution was used as a diluent for ML.

The values of the variables at basal condition were compared to those obtained during the infusion of ML, using Student's $t$ test for paired data. For all variables studied, the difference between the values obtained was considered significant when the statistical probability of its casualty was $<5 \%(\mathrm{p}<0.05)$.

\section{Results}

The maintenance dose of ML that determined the highest increase of CO was $0.500 \mu \mathrm{g} / \mathrm{kg} / \mathrm{min}$ in 3 patients, $0.625 \mu \mathrm{g} / \mathrm{kg} / \mathrm{min}$ in 4 patients and $0.750 \mu \mathrm{g} / \mathrm{kg} / \mathrm{min}$ in 13 patients (table I).

The results of the hemodynamic parameters obtained at basal condition and during the infusion of ML of all patients studied are shown in tables II and III, respectively.

When the results obtained at basal condition were compared to those obtained during the infusion of ML, the following could be observed: mild elevation of $\mathrm{HR}(+7.1 \%)$; significant reduction of MAP $(-10.9 \%)$, but in none of the patients analysed was the MAP less than $70 \mathrm{mmHg}$; significant reduction in MPAP (-28.8\%) and in MRAP (-37.9\%). 


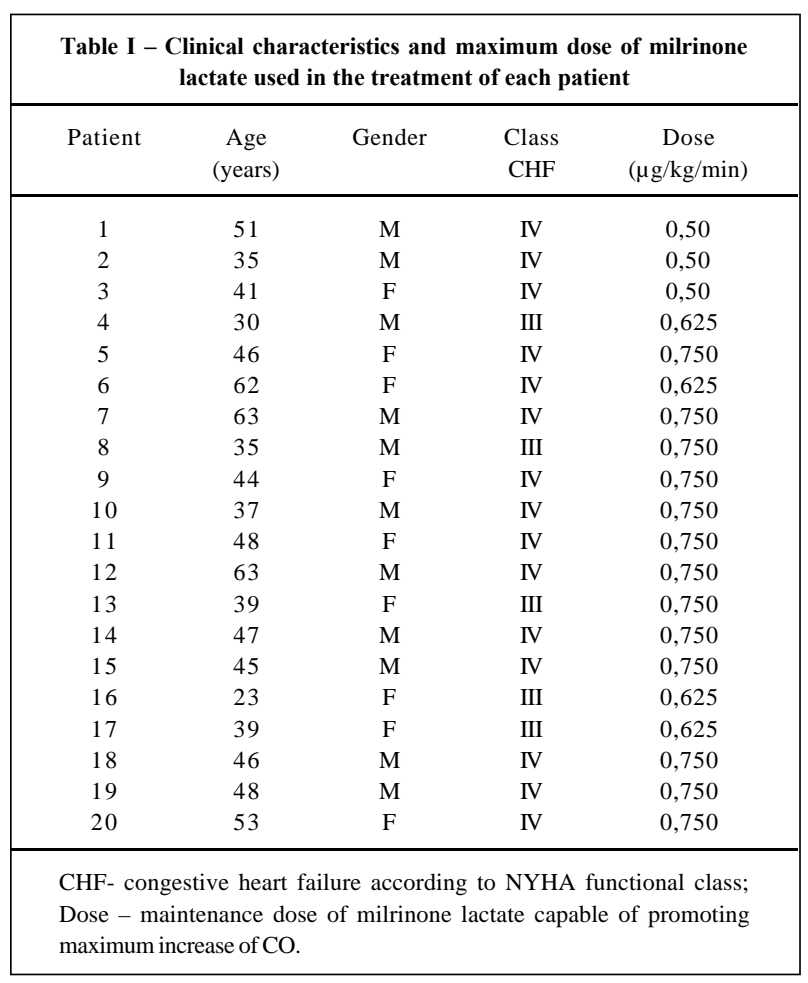

There was also significant reduction in PCWP (-40.2\%) and in LVEDP (-38.0\%). In regard to cardiac performance parameters, there was a significant increase in $\mathrm{CO}(+37.2 \%)$ and in $\mathrm{CI}(+37.8 \%)$ in all patients evaluated. There was also a significant reduction in PVR (-37.2\%) and in SVR (-30.3\%). In regard to $\mathrm{dP} / \mathrm{dt}$, there was a significant and dramatic increase $(+45.1 \%)$, characterizing the important positive inotropic effect of the drug. The percent variation of each parameter analysed is shown in figure 1 . There was significant improvement in PCWP, LVEDP, MPAP, MRAP, CI, SI, PVR, $\mathrm{SVR}$, and $\mathrm{dP} / \mathrm{dt}$, associated with a mild decrease in MAP and slight elevation of HR. None of the patients studied had adverse side effects that could justify the interruption of drug infusion. Five patients had isolated ventricular extrasystoles (not more than 10 ectopic beats per minute).

\section{Discussion}

The conventional treatment of patients with DCM and NYHA class III and IV CHF includes the administration of digitalis, diuretics, vasodilators, and the ACE inhibitor. Even with the use of rigid therapeutic regimens, a considerable number of these patients have frequent episodes of cardiac decompensation that require hospitalization and intravenous administration of inotropic drugs or vasodilators, or both. Among the inotropic drugs of intravenous use, besides the $\alpha$-adrenergic stimulants, the phosphodiesterase inhibitors (amrinone and milrinone) are useful agents in these conditions.

Milrinone lactate is a therapeutic agent of relatively recent use, with simultaneous positive inotropic and vasodilating activities. Therefore, it is a potentially promising drug for the treatment of patients with CHF, who do not respond satisfactorily to other drugs ${ }^{16-18}$.

\begin{tabular}{|c|c|c|c|c|c|c|c|c|c|c|c|}
\hline \multicolumn{12}{|c|}{$\begin{array}{l}\text { Table II - Individual values, means }(\overline{\mathrm{X}}) \text { and standard deviations (sd) of the hemodynamic variables, observed } \\
\text { at basal condition of all patients studied }\end{array}$} \\
\hline Patient & $\begin{array}{c}\mathrm{HR} \\
(\mathrm{bpm})\end{array}$ & $\begin{array}{c}\text { MAP } \\
(\mathrm{mmHg})\end{array}$ & $\begin{array}{l}\text { MRAP } \\
(\mathrm{mmHg})\end{array}$ & $\begin{array}{l}\text { MPAP } \\
(\mathrm{mmHg})\end{array}$ & $\begin{array}{l}\text { PCWP } \\
(\mathrm{mmHg})\end{array}$ & $\begin{array}{l}\text { LVEDP } \\
(\mathrm{mmHg})\end{array}$ & $\begin{array}{c}\mathrm{CO} \\
(1 / \mathrm{min})\end{array}$ & $\begin{array}{c}\mathrm{CI} \\
\left(1 / \mathrm{min} / \mathrm{m}^{2}\right)\end{array}$ & $\begin{array}{c}\text { PVR } \\
\left(\text { dyn } \times \mathrm{s} / \mathrm{cm}^{2}\right)\end{array}$ & $\begin{array}{c}\text { SVR } \\
(\text { dyn } \times \text { s/cm²) }\end{array}$ & $\begin{array}{c}\mathrm{dP} / \mathrm{dt}^{+} \\
(\mathrm{mmHg} / \mathrm{s})\end{array}$ \\
\hline 1 & 96 & 80 & 8 & 38 & 20 & 22 & 3,20 & 1,97 & 450 & 1800 & 918 \\
\hline 2 & 95 & 80 & 12 & 47 & 25 & 25 & 2,56 & 1,55 & 687 & 2125 & 1100 \\
\hline 3 & 100 & 75 & 8 & 65 & 32 & 30 & 2,88 & 1,90 & 917 & 1861 & 1000 \\
\hline 4 & 82 & 110 & 6 & 39 & 18 & 18 & 3,47 & 1,95 & 484 & 2398 & 987 \\
\hline 5 & 80 & 103 & 13 & 47 & 23 & 20 & 3,50 & 1,98 & 544 & 2056 & 1047 \\
\hline 6 & 85 & 93 & 9 & 56 & 25 & 23 & 3,83 & 2,23 & 647 & 1755 & 1051 \\
\hline 7 & 78 & 83 & 23 & 48 & 35 & 35 & 2,40 & 1,45 & 433 & 2000 & 1020 \\
\hline 8 & 84 & 86 & 9 & 38 & 18 & 17 & 3,31 & 2,36 & 483 & 1861 & 1000 \\
\hline 9 & 70 & 76 & 16 & 53 & 25 & 24 & 3,82 & 2,10 & 586 & 1256 & 987 \\
\hline 10 & 94 & 84 & 20 & 48 & 24 & 23 & 1,97 & 1,40 & 975 & 2599 & 960 \\
\hline 11 & 86 & 87 & 14 & 45 & 24 & 23 & 3,16 & 1,94 & 532 & 1848 & 1007 \\
\hline 12 & 90 & 80 & 8 & 33 & 20 & 20 & 1,94 & 1,20 & 536 & 2969 & 825 \\
\hline 13 & 110 & 93 & 13 & 43 & 25 & 24 & 2,66 & 1,74 & 541 & 2406 & 899 \\
\hline 14 & 100 & 91 & 14 & 44 & 24 & 25 & 2,56 & 1,66 & 625 & 2406 & 897 \\
\hline 15 & 100 & 106 & 11 & 45 & 34 & 33 & 3,51 & 2,21 & 251 & 2165 & 980 \\
\hline 16 & 80 & 92 & 7 & 35 & 27 & 26 & 3,03 & 1,64 & 211 & 2244 & 869 \\
\hline 17 & 90 & 80 & 6 & 32 & 20 & 20 & 2,50 & 2,50 & 315 & 1941 & 856 \\
\hline 18 & 82 & 87 & 14 & 46 & 24 & 26 & 2,80 & 1,97 & 604 & 2000 & 920 \\
\hline 19 & 90 & 80 & 12 & 44 & 22 & 24 & 2,50 & 1,88 & 704 & 2176 & 965 \\
\hline 20 & 76 & 75 & 10 & 48 & 27 & 27 & 2,42 & 2,01 & 700 & 2160 & 878 \\
\hline $\bar{x}$ & 88,4 & 87,0 & 11,6 & 44,7 & 24,6 & 24,2 & 2,90 & 1,85 & 561,0 & 2101 & 908,3 \\
\hline $\mathrm{sd}$ & 14,5 & 10 & 5,6 & 8,7 & 5,8 & 5,6 & 0,86 & 0,26 & 51,0 & 176,2 & 113,4 \\
\hline $\begin{array}{l}\text { HR- heart } \\
\text { pressure; } \\
\text { resistance }\end{array}$ & $\begin{array}{l}\text { MAP- } \\
P-1 \mathrm{l}\end{array}$ & $\begin{array}{l}\text { aortic } \\
\text { tricle e }\end{array}$ & $\begin{array}{l}\text { Ire; PC } \\
\text { stolic }\end{array}$ & almona & $\begin{array}{l}\text { pillary } \\
\text { ac out }\end{array}$ & I- card & 111 & Imonary & 1 picsou & IRAP- mea & $\begin{array}{l}\text { ght atrium } \\
\text { c vascular }\end{array}$ \\
\hline
\end{tabular}




\begin{tabular}{|c|c|c|c|c|c|c|c|c|c|c|c|}
\hline \multicolumn{12}{|c|}{$\begin{array}{l}\text { Table III - Individual values, means and standard deviations (sd) of the hemodynamic variables observed during infusion of } \\
\text { milrinone lactate in all patients studied }\end{array}$} \\
\hline Patient & $\begin{array}{c}\mathrm{HR} \\
(\mathrm{bpm})\end{array}$ & $\begin{array}{l}\text { MAP } \\
(\mathrm{mmHg})\end{array}$ & $\begin{array}{l}\text { MRAP } \\
(\mathrm{mmHg})\end{array}$ & $\begin{array}{l}\text { MPAP } \\
(\mathrm{mmHg})\end{array}$ & $\begin{array}{l}\text { PCWP } \\
(\mathrm{mmHg})\end{array}$ & $\begin{array}{l}\text { LVEDP } \\
(\mathrm{mmHg})\end{array}$ & $\begin{array}{c}\mathrm{CO} \\
(1 / \mathrm{min})\end{array}$ & $\begin{array}{c}\mathrm{CI} \\
\left(1 / \mathrm{min} / \mathrm{m}^{2}\right)\end{array}$ & $\begin{array}{c}\text { PVR } \\
(\text { dyn } \times \text { s/cm²) }\end{array}$ & $\begin{array}{c}\text { SVR } \\
\left(\text { dyn } \times \text { s } / \mathrm{cm}^{2}\right)\end{array}$ & $\begin{array}{r}\mathrm{dP} / \mathrm{dt}^{+} \\
(\mathrm{mmHg} / \mathrm{s})\end{array}$ \\
\hline 1 & 100 & 73 & 6 & 19 & 14 & 15 & 3,80 & 2,35 & 105 & 1410 & 1133 \\
\hline 2 & 100 & 70 & 7 & 40 & 14 & 16 & 2,89 & 1,75 & 720 & 1744 & 1700 \\
\hline 3 & 106 & 70 & 6 & 53 & 23 & 23 & 3,46 & 2,28 & 694 & 1460 & 1432 \\
\hline 4 & 85 & 81 & 4 & 17 & 10 & 9 & 4,26 & 2,39 & 131 & 1446 & 1343 \\
\hline 5 & 85 & 90 & 13 & 20 & 10 & 10 & 4,82 & 2,80 & 166 & 1278 & 1639 \\
\hline 6 & 91 & 88 & 3 & 44 & 15 & 13 & 5,36 & 3,12 & 433 & 1269 & 1342 \\
\hline 7 & 88 & 72 & 13 & 35 & 22 & 23 & 4,79 & 2,88 & 217 & 985 & 1346 \\
\hline 8 & 95 & 83 & 4 & 15 & 10 & 10 & 3,91 & 2,79 & 102 & 1616 & 1247 \\
\hline 9 & 85 & 70 & 7 & 43 & 16 & 20 & 4,64 & 2,55 & 465 & 931 & 1143 \\
\hline 10 & 100 & 70 & 10 & 40 & 11 & 15 & 3,58 & 2,54 & 648 & 1328 & 1358 \\
\hline 11 & 88 & 76 & 8 & 33 & 15 & 16 & 4,15 & 2,55 & 347 & 1311 & 1338 \\
\hline 12 & 98 & 76 & 4 & 22 & 14 & 14 & 2,70 & 1,67 & 237 & 2133 & 1137 \\
\hline 13 & 120 & 79 & 7 & 35 & 14 & 13 & 4,63 & 3,03 & 363 & 1244 & 1526 \\
\hline 14 & 106 & 78 & 6 & 34 & 12 & 11 & 4,51 & 2,93 & 390 & 1277 & 1437 \\
\hline 15 & 102 & 89 & 8 & 40 & 24 & 26 & 3,88 & 2,44 & 330 & 1629 & 1115 \\
\hline 16 & 84 & 88 & 4 & 32 & 15 & 16 & 4,49 & 2,43 & 303 & 1497 & 1034 \\
\hline 17 & 98 & 76 & 5 & 22 & 14 & 14 & 3,05 & 2,61 & 256 & 2272 & 1137 \\
\hline 18 & 86 & 80 & 8 & 32 & 15 & 14 & 4,02 & 2,48 & 340 & 1440 & 1336 \\
\hline 19 & 94 & 72 & 6 & 30 & 13 & 12 & 3,51 & 2,62 & 388 & 1504 & 1438 \\
\hline 20 & 82 & 68 & 5 & 30 & 13 & 15 & 3,30 & 2,88 & 412 & 1520 & 1237 \\
\hline $\bar{x}$ & 94,7 & $77,5^{*}$ & $7,2^{*}$ & $31,8^{*}$ & $14,7^{*}$ & $15,0 *$ & $3,98^{*}$ & $2,55^{*}$ & $352 *$ & $1464 *$ & $1317 *$ \\
\hline $\mathrm{sd}$ & 13,2 & 8,2 & 3,1 & 5,4 & 4,2 & 4,1 & 0,90 & 0,30 & 46,2 & 126,0 & 108,7 \\
\hline
\end{tabular}

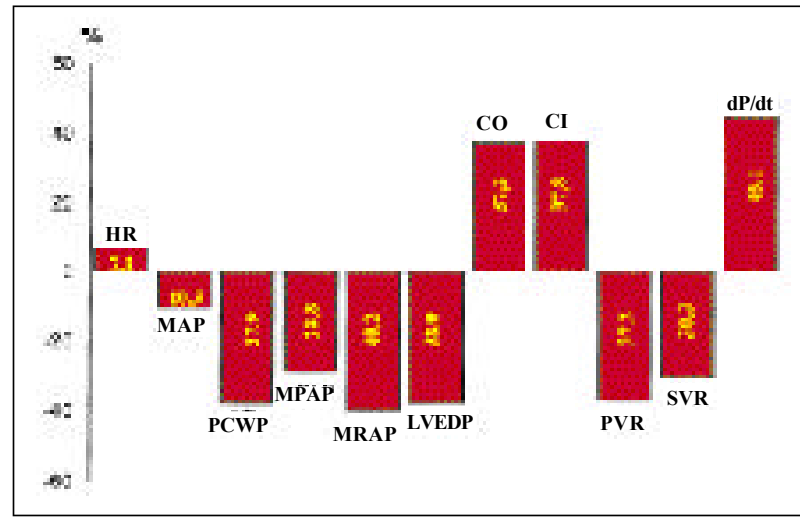

Fig. 1 - Percent variation of variables studied observed at basal condition and during infusion of milrinone lactate. HR- heart rate; MAP- mean aortic pressure; PCWPpulmonary capillary wedge pressure; MPAP- mean pulmonary artery pressure; MRAP- mean right atrium pressure; LVEDP- left ventricle end-diastolic pressure; COcardiac output; CI- cardiac index; PVR- pulmonary vascular resistance; SVR- systemic vascular resistance; $\mathrm{dP} / \mathrm{dt}+$ - peak rate of left ventricular pressure rise.

In DCMs, the primary and major functional disorder is the depression of myocardial contractility, which results in a decrease systolic function and reduction of $\mathrm{CO}$. The reduction of CO leads to a series of complex mechanisms of compensation, with special emphasis on the adrenergic hyperactivity, the activation of the renin-angiotensin-aldosterone system, and the increased release of the arginine-vasopressin complex ${ }^{19}$. In an initial stage, these mechanisms stimulate contractility, increasing the $\mathrm{CO}$, maintaining the flow to vital organs, and promoting the expansion of blood volume. The consequence is the increase in afterload and preload (the first results from vasoconstriction and the second from sodium and water retention). When $\mathrm{CHF}$ becomes chronic, these mechanisms can cause undesired effects, such as exaggerated elevation of preload and afterload, as well as reduction of density and sensitivity of the myocardial $\beta$-receptors, due to their prolonged exposure to high levels of circulating norepinephrine ${ }^{6,20}$. The reduction of myocardial $\beta$-receptors deprives the failing heart of this main compensatory mechanism and can restrict the activity of the inotropic agents, which act through the $\beta$-adrenergic pathway.

Under these conditions, the inhibitors of phosphodiesterase (amrinone and milrinone) can promote an increase in myocardial contractility through a different mechanism from those of the sympathicomimetic agents. The effect of ML through the inhibition of the fraction III of phosphodiesterase results in the increase in the concentration of cyclic AMP and $\mathrm{Ca}^{++}$inside muscle cells ${ }^{14}$. The increase of $\mathrm{Ca}^{++}$influx occurs through the slow calcium channels, producing positive inotropic and vasodilating effects. The positive inotropic effect is believed to be linked to the modulation of capture and release of calcium by the sarcoplasmic reticulum inside myocardial cells ${ }^{10}$. The vasodilating effect is due to a vessel-relaxing action produced by the phosphorylation of proteins of the smooth muscle of the vessels by protein kinases dependent on cyclic AMP and by changes in ionic flows ${ }^{10,12,14,21}$. This combined effect increases myocardial contractility and simultaneously reduces the cardiac load through vasodilating action, which justifies the use of ML in the treatment of CHF, replacing the sympathicomimetic agents or associated with them. 
This study demonstrates that the intravenous administration of ML results in beneficial hemodynamic effects, improvement in myocardial contractility, and reduction in pulmonary and systemic vascular resistance in all patients analysed.

The improvement of LV performance can be evidenced by the significant increase of $\mathrm{CO}$ and $\mathrm{CI}$ along with the reduction of PCWP and LVEDP. Parallel to the improvement in cardiac performance indexes, we also verified reduction in MPAP, MAP, and the values of SVR and PVR, which, along with the increase in $\mathrm{CO}$ and decrease in the values of systemic and pulmonary blood pressure, characterize the vasodilating effect of ML. Furthermore, the decrease in MRAP concomitant with the elevation in $\mathrm{CO}$ and reduction of SVR and PVR suggest a vasodilating effect on the vessels of the venous capacitance.

The effect of ML in cardiac inotropism is demonstrated by the significant elevation in the values of $\mathrm{dP} / \mathrm{dt}$ in all patients studied. It should be emphasized, however, that the positive inotropic effect might be underestimated because this index is influenced by the conditions of cardiac load ${ }^{22-25}$. Because $\mathrm{dP} / \mathrm{dt}$ is an index of the pre-ejection stage, the reduction of the systemic blood pressure associated with the reduction of LVEDP due to ML might have restricted a more significant increase in the values of $\mathrm{dP} /$ $\mathrm{dt}$, which characterize the positive inotropic effect of the drug. Several clinical trials have investigated the effects of ML in patients without ${ }^{26}$ and patients with CHF of different levels and causes 11,14,16,17,21,27-29. These studies demonstrated that, when administered in the form of bolus or of intravenous continuous infusion, ML improves $\mathrm{CO}$ and $\mathrm{CI}$, myocardial contractility $(\mathrm{dP} / \mathrm{dt})$, as well as reduces MAP, SVR, MRAP, and LVEDP. These hemodynamic effects were not accompanied by significant elevation in $\mathrm{HR}^{30,31}$ and in myocardial oxygen consumption ${ }^{4,28,30,32,33}$. Jaski et al ${ }^{5}$ compared the hemodynamic effects of ML with those of sodium nitroprusside, which has only vasodilating activity. They demonstrated that ML promoted a higher elevation in $\mathrm{CO}$ and $\mathrm{dP} / \mathrm{dt}$, with equivalent grades of blood pressure reduction, thus confirming the positive inotropic effect of this agent.
The beneficial effects in the indexes of cardiac performance, myocardial contractility, and systemic and pulmonary arterial vasodilatation observed in this study are in accordance with several studies of in vitro preparations ${ }^{34,35}$ and with clinical trials ${ }^{5,16,17,27,31,33}$, which showed that ML has a strong positive inotropic effect associated with arterial vasodilatation. These studies also revealed that vasodilating effects tend to compensate the inotropic effects in the myocardial oxygen demand, resulting in an increase of $\mathrm{CO}$, with minimum changes in myocardial oxygen consumption ${ }^{4,28,30,32,33}$. We also emphasize that ML action is hardly affected by the reduction or dissociation of $\beta$-adrenergic receptors, commonly present in patients with severe $\mathrm{DCM}^{6,7}$, because the inotropic action of this drug does not involve the $\beta$-adrenergic pathway. Therefore, considering the information available in the literature, we can state that ML is an inodilator potentially useful in the treatment of patients with DCM and severe CHF. The drug enhances myocardial contractility concomitantly with the reduction of preload and afterload, without significantly increasing myocardial oxygen consumption, and promotes positive inotropic action even when the activity of $\beta$-receptors is impaired. This fact turns this agent into a potentially useful treatment for patients with DCM and severe CHF.

The results of this work are in accordance with the data in the literature and prove that ML is an effective inodilator in the short-term treatment of patients with DCM and class III and IV CHF. It was proved that the intravenous infusion of this agent was followed by a significant increase in the indexes of cardiac performance, significant increase in myocardial contractility, reduction of preload and afterload without significantly interfering with HR. The activities of the drug are compatible with beneficial cardiovascular effects with no increase, or only mild changes, in the consumption of myocardial oxygen.

Therefore, we conclude that ML is a therapeutic agent with effective cardiovascular activities. It can and should be used in the treatment of episodes of heart failure in patients with DCM and severe myocardial involvement.

\section{References}

1. Leiel CV, Heban PT, Huss P - Comparative systemic and regional effects of dopamine and dobutamine on patients with cardiomyopathic heart failure. Circulation 1978; 58: 466-75.

2. Van Trigt P, Spray TL, Pasque MK - The comparative effects of dopamine and dobutamine on ventricular mechanics after coronary artery bypass grafting: a pressure-dimensions analysis. Circulation 1984; 70(suppl): I-112-17.

3. Colucci SW, Richard FW, Jaski BE, Fifer MA, Braunwald E-Milrinone and dobutamine in severe heart failure: differing hemodynamic effects and individual patient responsiveness. Circulation 1986; 73: 175-83.

4. Grose R, Strain J, Greenberg M, Lejemtel TH - Systemic and coronary effects of intravenous milrinone and dobutamine on congestive heart failure. J Am Coll Cardiol 1986; 7: 1107-113.

5. Jaski BE, Fifer MA, Wright RF, Braunwald E, Colucci WS - Positive inotropic and vasodilating actions of milrinone in patients with severe congestive heart failure. Dose-response relationships and comparison to nitroprussiate. J Clin Invest 1985; 75: 643-59.

6. Bristow MR, Ginsburg R, Minobe W, et al - Decreased catecholamine sensitivity and $\beta$-adrenergic-receptor density in failing human hearts. N Engl J Med 1982; 307: 205-10.

7. Bristow MR - The adrenergic system in heart failure. N Engl J Med 1984; 311 : 350-61.

8. Farah AE, Alonsi AA - New cardiotonic agents: a research for digital substitute. Life 1978; 22: 1139-41.

9. Joseph B, Grossman W, Braunwald E, Alonsi AA - Hemodynamic assessment of amrinone. A new inotropic agent. N Engl J Med 1978; 299: 1373-7.

10. Earl CQ, Linden J, Weglicki WB - Biochemical mechanisms for the inotropic effect of the cardiotonic drug milrinone. J Cardiovasc Pharmacol 1986; 8: 864-72.

11. Bianco RD - Acute positive inotropic intervention: the phosphodiesterase inhibitors. Am Heart J 1991; 121: 1371-8. 
12. Evans DB - Overview of cardiovascular physiology and pharmacologic aspects of selective phosphodiesterase peak III inhibitors. Am J Cardiol 1989; 63: 9A-11A.

13. Scholz H, Meyer W-Phosphodiesterase inhibiting properties of new inotropic agents. Circulation 1986; 73(suppl III): 99-108.

14. Forister PE-Amrinone, milrinone and enoxinone. In: Eny GA, Bressler R. eds Cardiovascular Drugs and Management of Heart Disease, $2^{\text {nd }}$ ed. New York: Raven Press, 1992: 83-8.

15. Matsubara BB, Bregagnollo EA, Ribeiro MACL, Tucci PJF - Relações pressão/ diâmetro e esforço/diâmetro do ventrículo esquerdo em seres humanos. Padronização e análise crítica do método. Arq Bras Cardiol 1990; 54: 373-81.

16. Baim DS, McDowell AV, Chermilles J - Evaluation of a new bipiridine agent milrinone in patients with severe congestive heart failure. N Engl J Med 1983; 309: 748-56.

17. Maskin CS, Sinoway L, Chadwick B, Sonnenblick EH - Sustained hemodynamic and clinical effects of a new cardiotonic agent WIN 47203 on patients with severe congestive heart failure. Circulation 1983; 67: 1065-70.

18. Braunwald E, Covell JW - Evaluation of the efficacy of new inotropic agents. J Am Coll Cardiol 1984; 3: 1570-4.

19. Parmley WW - Pathophysiology and current therapy of congestive heart failure. J Am Coll Cardiol 1989; 13: 771-85.

20. Bristow MR, Hershberger RE, Port JD, et al - Beta-adrenergic pathways in non-failing and failing human ventricular myocardium. Circulation 1990; 82(suppl): 12-15.

21. Silver PJ, Lepore RE, O'Connor B - Inhibition of the low km cyclic AMP phosphodiesterase and activation of the cyclic system in vascular smooth muscle by milrinone. J Pharmacol Exp Ther 1988; 247: 34-42.

22. Gleason WL, Braunwald E-Studies on the first derivative of the ventricula pulse in man. J Clin Invest 1961; 41: 80-91.

23. Wallace AG, Skiner NS, Mitche JH-Hemodynamic determinants of the maximal rate of left ventricular pressure. Am J Physiol 1963; 205: 30-6.

24. Bregagnollo EA, Matsubara BB, Tucci PJF - Influência da elevação transitória e sustentada da pressão arterial sobre a primeira derivada temporal da pressão ventricular esquerda. Arq Bras Cardiol 1992; 58: 437-43.
25. Quinones MA, Gaash WH, Alexander JK - Influence of acute changes in preload, afterload, contractile state and heart rate on ejection and isovolumic indices of myocardial contractility in man. Circulation 1976; 52: 293-302.

26. Borow KM, Come PC, Neumann A, Baim DS, Braunwald E, Grossman W Physiologic assessment of inotropic, vasodilating and afterload reducing effects of milrinone on subjects without cardiac disease. Am J Cardiol 1985; 55 1204-9.

27. Sonnenblick EH, Grose R, Strain J, Zelcer AA, Lejemtel TH-Effects of milrinone on left ventricular performance and myocardial contractility in patients with severe heart failure. Circulation 1986; 73(suppl III): 162-7.

28. MonradES, Bain DS, S mith HS, Lanone B, Braunwald E, Grossman W-Effects of milrinone on coronary hemodynamics and myocardial energetics in patients with congestive heart failure. Circulation 1985; 71: 972-9.

29. Cody RJ, Muller FB, Kubo SH, Rutman H, Leonard D-Identification of the direct vasodilating effect of milrinone with chronic congestive heart failure. Circulation 1986; 73: 124-9.

30. Young RA, Ward A-Milrinone: a preliminary review of its pharmacologica properties and therapeutical use. Drugs 1988; 36: 158-92.

31. Gun C, Piegas LS, Bianco ACM, Freire RBP, Ramos RF, Timerman A - Valor do uso da milrinona no tratamento das crises de agudização em portadores de insuficiência cardíaca congestiva. Arq Bras Cardiol 1995; 65: 255-8

32. Bain DS - Effect of phosphodiesterase inhibition on myocardial oxygen consumption and coronary blood flow. Am J Cardiol 1989; 63: 23A-6A

33. Monrad ES, Bain DS, Smith HS, Lanone AS - Milrinone, dobutamine and nitroprussiate: comparative effects on hemodynamics and myocardial energetics in patients with severe congestive heart failure. Circulation 1986; 73(suppl III): 168-74.

34. Alonsi AA, Canter JM, Montenaro MJ, Fort DJ, Ferrari RA - Cardiotonic activity of milrinone: a new and potent cardiac bipiridine stimulant on the normal and failing heart of experimental animal. J Cardiovasc Pharmacol 1983; 5: 792-803.

35. Alonsi AA, Stankus GP, Stuart JC, Walton LH - Characterization of the cardiotonic effect of milrinone on isolated tissues from several animal species. J Cardiovasc Pharmacol 1983; 5: 804-11. 